\title{
Contribution of advanced fluorescence nano microscopy towards revealing mitotic chromosome structure
}

\author{
S W. Botchway \\ Rutherford Appleton Laboratory, Research Complex at Harwell, Oxford, UK. \\ Safana Farooq \\ Aga Khan University, safana.farooq@aku.edu \\ A Sajid \\ Aga Khan University \\ I K. Robinson \\ University College London, London, UK. \\ Mohammed Yousuf \\ Aga Khan University, mohammed.yusuf@aku.edu
}

Follow this and additional works at: https://ecommons.aku.edu/crm

Part of the Cell Biology Commons

\section{Recommended Citation}

Botchway, S. W., Farooq, S., Sajid, A., Robinson, I. K., Yousuf, M. (2021). Contribution of advanced fluorescence nano microscopy towards revealing mitotic chromosome structure. Chromosome Research. Available at: https://ecommons.aku.edu/crm/67 


\title{
Contribution of advanced fluorescence nano microscopy towards revealing mitotic chromosome structure
}

\author{
S. W. Botchway $\cdot$ S. Farooq $\cdot$ A. Sajid $•$ \\ I. K. Robinson $\cdot$ M. Yusuf $\mathbb{C}$
}

Received: 3 December 2020 / Revised: 4 February 2021 / Accepted: 8 February 2021

(C) The Author(s) 2021

\begin{abstract}
The organization of chromatin into higherorder structures and its condensation process represent one of the key challenges in structural biology. This is important for elucidating several disease states. To address this long-standing problem, development of advanced imaging methods has played an essential role in providing understanding into mitotic chromosome structure and compaction. Amongst these are two fast evolving fluorescence imaging technologies, specifically fluorescence lifetime imaging (FLIM) and superresolution microscopy (SRM). FLIM in particular has been lacking in the application of chromosome research while SRM has been successfully applied although not
\end{abstract}

S. Farooq and A. Sajid are joint authors

Responsible Editor: Kiichi Fukui and Toshiyuki Wako

S. W. Botchway

Central Laser Facility, Science and Technology Facilities Council (STFC) Rutherford Appleton Laboratory, Research Complex at Harwell, Oxford, UK

S. Farooq · A. Sajid $\cdot$ M. Yusuf $(\bowtie)$

Centre for Regenerative Medicine and Stem Cell Research, Aga

Khan University, P.O.Box 3500, Karachi 74800, Pakistan

e-mail: mohammed.yusuf@aku.edu

e-mail: ucanymo@ucl.ac.uk

I. K. Robinson • M. Yusuf

London Centre for Nanotechnology, University College London, London WC1H 0AH, UK

I. K. Robinson

Brookhaven National Lab, Upton, NY 11973, USA widely. Both these techniques are capable of providing fluorescence imaging with nanometer information. SRM or "nanoscopy" is capable of generating images of DNA with less than $50 \mathrm{~nm}$ resolution while FLIM when coupled with energy transfer may provide less than $20 \mathrm{~nm}$ information. Here, we discuss the advantages and limitations of both methods followed by their contribution to mitotic chromosome studies. Furthermore, we highlight the future prospects of how advancements in new technologies can contribute in the field of chromosome science.

Keywords cytogenetics - chromosome - chromatin . fluorescence microscopy $\cdot$ fluorescence lifetime imaging · time-resolved · super-resolution microscopy

\section{Introduction}

Microscopy has contributed hugely in the field of chromosome science since they were first observed in the 1900s. Early light microscopy observations showed that chromosomes are packaged into the cell's nucleus. Further microscopy observations revealed that chromatin (composed of deoxyribonucleic acid (DNA) and nucleosome clusters) has territorial organization (Rabl 1885; Boveri 1909; Cremer and Cremer 2010) displaying fibers during interphase and as condensed individual structures in metaphase. Chromosomes are specie dependent having a different number and displaying huge diversity. The discovery of 46 chromosomes in human 
allowed all chromosomes to be ranked according to their respective cytogenetic groups based on their size and shape into a karyotype (Tjio and Levan 1956). This led to the identification of anomalies both numerical (Lejeune 1959; Ford et al. 1959; Jacobs and Strong 1959; Jacobs et al. 1959; Sandberg et al. 1961) and structural (Nowell and Hungerford 1960). The identification of these changes is used routinely in hospital cytogenetic labs after performing g-banded (karyotyping) (Sumner 1982), for the diagnosis of a number of hematological malignancies and prenatal /genetic medical disorders (Tobias et al. 2011).

In addition, the use of fluorescence microscopy has also been an important clinical diagnostic tool allowing identification of specific disease loci using fluorescence in situ hybridization (FISH) technology (Levsky and Singer 2003; Volpi and Bridger 2008). Karyotyping using multicolor FISH technology has provided further advantages in identifying complex structural and numerical aberrations (Speicher et al. 1996; Schröck et al. 1996; Yusuf et al. 2011, 2013).

The structure of chromosomes has been widely explored using a number of imaging methods. Mitotic chromosomes are visualized using light/fluorescence microscopy that display chromatin into two structural states, heterochromatin (late replicating-gene poor-condensed-GC rich-dark G-bands) and euchromatin (early replicating-gene rich-loose-AT rich-light G-bands) (Holmquist and Ashley 2006). As light/FL microscopy is limited to the diffraction limit of $200 \mathrm{~nm}$ resolution (Abbe 1873), advanced microscopes that surpass this resolution limit have provided further insights into the higher-order structure of mitotic chromosomes (Yusuf et al. 2014, 2019; Chen et al. 2017). Organization levels of chromosomes using different microscopy methods are illustrated in Fig. 1 (Flors and Earnshaw 2011). Xray crystallography solved the first-level structure that comprised of DNA wrapped around a histone octamer (H2A, H2B, H3, and H4) (Davey et al. 2002; Luger et al. 1997). Electron microscopy showed 11-nm "beads on a string"-like structure (Olins and Olins 1974) linked by Histone H1 proteins (Woodcock et al. 2006). The binding of the linker histone (H1 or H5) organizes the nucleosome arrays into a more condensed chromatin fiber (Robinson et al. 2006). A 30-nm structure has been proposed whose existence remains debatable (Maeshima et al. 2016; Krietenstein and Rando 2020; Yusuf et al. 2019). Many models have been proposed that have been discussed elsewhere (Bendandi et al.
2020; Ohno et al. 2018; Yusuf et al. 2019). However, several studies have not conclusively supported the 30$\mathrm{nm}$ fiber existence including the small angle X-ray scattering (SAXS) performed in solution that supports the 10-nm fiber (Joti et al. 2012; Nishino et al. 2012) and in vivo studies (Maeshima et al. 2010; Fussner et al. 2011). A "polymer-melt" model has been suggested whereby the nucleosome fibers may be moving and rearranging at the local level (Nishino et al. 2012; Maeshima et al. 2014). Heterogeneous groups of nucleosomes called "nucleosome clutches" were visualized using super-resolution microscopy (SRM) using mouse cells in situ and showed 10-nm fibers (Ricci et al. 2015). It is interesting to note that $30-\mathrm{nm}$ chromatin fibers have frequently been observed by scanning electron microscopy (SEM) (Inaga et al. 2008), scanning transmission electron microscopy (STEM) (Fukui 2016), and cryoEM (Robinson et al. 2006; Eltsov et al. 2014). Cryo-EM of frozen hydrated sections of both chromosomes and nuclei has shown the 30-nm chromatin structures in aldehyde-fixed samples that were not seen after cryopreservation (Eltsov et al. 2014). ChromEMT that is a multitilt EM tomography and a labelling method that enhances the contrast of DNA showed that nucleosomes are organized into disordered chains. These have diameters ranging between 5 and $24 \mathrm{~nm}$, highlighting that the 10 -nm fiber is probably highly heterogeneous and varies in diameter (Ou et al. 2017).

The challenge has been in elucidating the high-order inner structure and topology of chromatin fibers that remain unsolved (Maeshima et al. 2010; Krietenstein and Rando 2020; Yusuf et al. 2019, 2020).

Fluorescence microscopy has contributed hugely to the study of mitotic chromosomes (Balchand et al. 2016; Rieder and Khodjakov 2003; Belmont 2001). Chromosome imaging is achieved after labelling the chromosomal DNA using fluorescent dyes and applying FISH (Volpi and Bridger 2008; Lipinski et al. 2011). Dyes can be incorporated using clickchemistry-based strategies such as 5-Ethynyl-2'deoxyuridine (EdU) incorporation (Ishizuka et al. 2016) and more recently the CRISPR/Cas 9 technology (Ma et al. 2015; Zhou et al. 2017). Chromosomal proteins are visualized following transfecting cells with green fluorescent protein (GFP) tagging (Kanda et al. 1998) and also after immunostaining (Samejima et al. 2012). The discovery of GFP was awarded the Nobel Prize in Chemistry jointly to Osamu Shimomura, Martin Chalfie, and Roger Y. Tsien in 
Fig. 1 Microscopy methods used to study different chromatin hierarchical chromatin states. (Reproduced with permission from Flors and Earnshaw 2011)

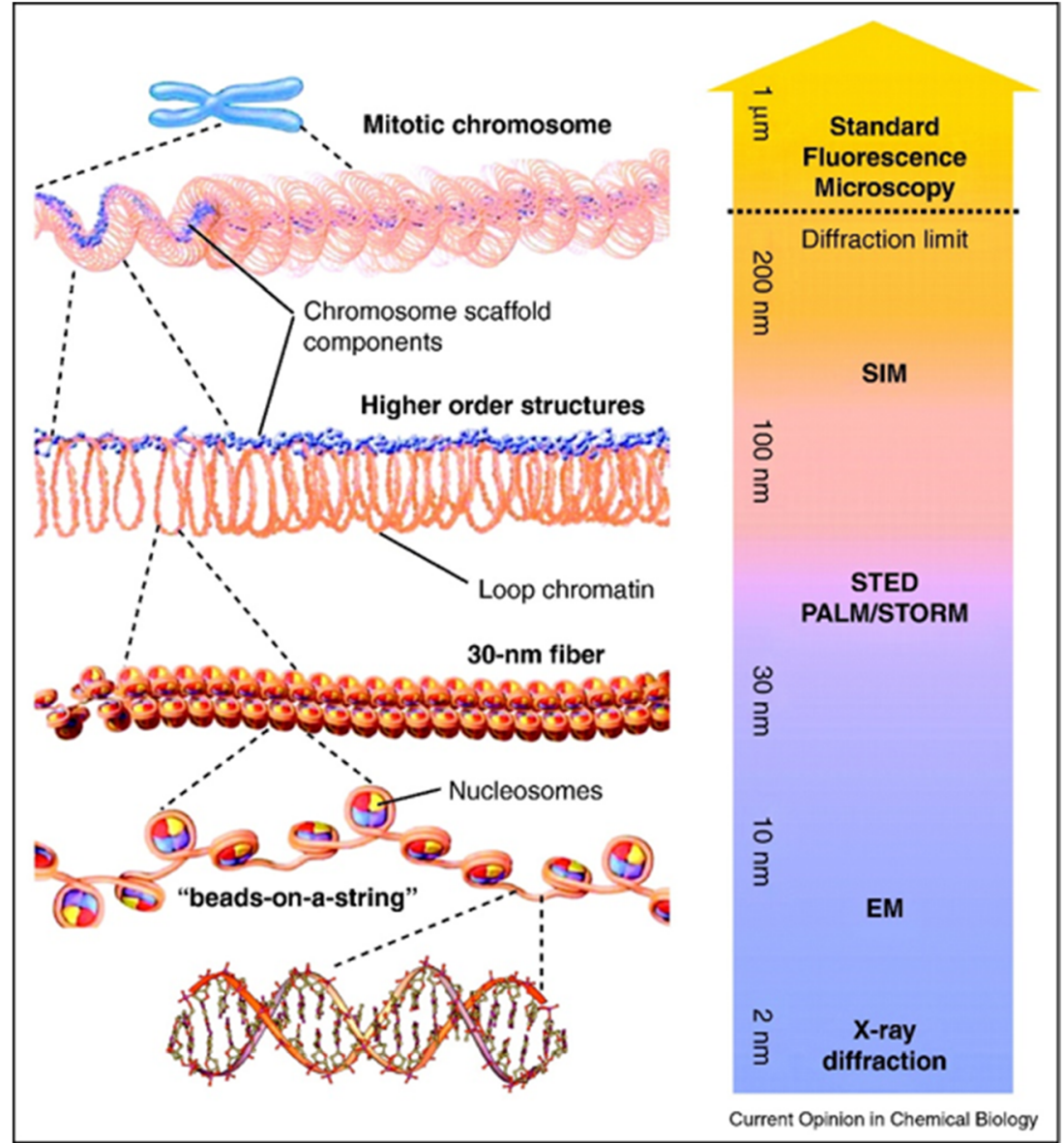

2008 (Tsien 2010). The use of GFP towards chromosome imaging involves largely imaging proteins associated with DNA, for example histones. GFP technology requires the expression of the protein which is tagged; hence, this is an indirect method to fluorescently visualize chromosomes. The advantages here open the possibility of imaging chromosome structure in live cells in real time and under physiological conditions (Kanda et al. 1998). We have used GFP tagged to the DNA repair protein $\mathrm{Ku} 70 / 80$ to visualize metaphase chromosomes during DNA damage and repair in real time (Botchway n.d.).

Even though microscopy has contributed tremendously, we still are limited in our understanding of how chromatin condenses in mitotic chromosomes and how nucleosomes organize during this process, particularly at the early times of chromosome condensation and in live cells. Advanced fluorescence microscopes have the potential to provide deeper insights into both the structure and compaction of mitotic chromosomes under physiological conditions compared to X-ray and cryoelectron microscopy. These FL microscopy methods include florescence lifetime imaging microscopy (FLIM) and the many forms of SRM. In this review, we highlight the contribution of FLIM and a number of SRM approaches for investigating mitotic chromosomes. We further discuss the limitations and future directions.

\section{Fluorescence lifetime imaging microscopy}

FLIM utilizing confocal single and multiphoton excited state emission microscopy together with time-correlated single-photon counting (TCSPC) provides an unambiguous determination of the location and environment of fluorophores. FLIM may also be performed using the time-gated intensified charged coupled devices (ICCD) with pulsed (nanosecond pulse width) light sources in an epifluorescence configuration. The use of frequency- 
domain lifetime imaging has also been described (Lakowicz 2006). However, the spatial resolution and time responses of these systems are poor compared to the TCSPC-FLIM system which we have employed over many years (Botchway et al. 2015). While the operation of these other systems varies, the data interpretation is similar. The principle of a TCSPC-FLIM system is shown in Fig. 2 (Becker 2019).

The fluorescence lifetime for a particular chromophore in a particular environment is fixed and defines the average time the molecule spends in the excited state before returning to the ground state, which is typically in the range of several nanoseconds (ns). Thus using FLIM, the excited state lifetime of a sample can be measured and imaged. Changes in the life values reflect the fluorophore's environment such as $\mathrm{pH}$, viscosity, proximity to other molecules and energy transfer events via dipole-dipole interactions. All these can be determined under physiological conditions. The emission of a fluorescence photon from a fluorophore is measured over a distributed time and is a function of an exponential decay (Bacskai et al. 2003; Berezin and Achilefu 2010). An important mechanism of which FLIM has significant advantage is the Forster resonance energy transfer (FRET) that can detect direct protein-protein or proteinDNA interactions. FRET is a quenching process that depletes the excited state of the donor fluorophore in the presence of an acceptor molecule or moiety, so that the donor fluorescence lifetime is shortened during FRET. This intermolecular or intramolecular energy transfer occurs at distances on a nanometer scale (1$10 \mathrm{~nm}$ ). This allows for conformational changes (Suhling et al. 2015; Lakowicz 2006). Fluorescence lifetime has drastically improved the structural and functional information obtained from biological samples compared to the fluorescence intensity alone. Several factors including fluorophore concentration, photo-bleaching, and limited sensitivity of detectors hamper the quality and quantification of the intensity information. Often these are not corrected for in steady-state FL microscopy. In contrast, FLIM is less influenced by the aforementioned factors and provides lifetime-based contrast (Abdollahi et al. 2018; Estandarte et al. 2016; Murata et al. 2001). Although the majority of FLIM currently performed is still at the diffraction-limited resolution, it is now possible to perform FLIM at resolutions below $50 \mathrm{~nm}$ (see below) (Lesoine et al. 2012). This paves the way for imaging chromosome structures of around $30 \mathrm{~nm}$ and below using FLIM.

\section{FLIM for examining compaction in chromosomes}

FLIM serves as powerful tools to study chromatin condensation (including compaction states) in both live and fixed samples mainly because the nucleosome coiling resides within 1-10 $\mathrm{nm}$ resolution. Using FRET-FLIM, Llères et al. (2009) have performed time-lapse studies of the compaction and the spatial organization of chromatin on the same cell (Llères et al. 2009). However, the number of studies done on investigating chromatin compaction and other structural characteristics using FLIM is limited. Below we summarize recent research studies.

FLIM has been used to study the chromatin compaction state during cell cycle progression in fixed samples where heterogeneous DNA distribution was seen (Murata et al. 2000; Murata et al. 2001; Görlitz et al. 2017). FLIM on live interphase nuclei has shown chromatin decompaction upon chemical or radiation stimulus (Abdollahi et al. 2018; Lou et al. 2019; Pelicci et al. 2019; Sherrard et al. 2018). Live cell imaging studies have examined naive embryonic stem cells (ESCs) undergoing differentiation and showed that the presence of NANOG is essential for chromatin decompaction during pluripotency together with Rex1 downregulation (Hockings et al. 2020). Furthermore, ATP depletion in ESCs leads to reduction in chromatin movement hindering transcription regulation during pluripotency (Hinde et al. 2012). It has been shown that chromatin relaxation affects the distribution of multiple splicing factors and any perturbation of chromatin structure impairs the recruitment of regulatory splicing factors to pre-mRNA (Schor et al. 2012). Spontaneous chromatin condensation fluctuations have shown to be responsible for the accessibility of acetylated Histone H4 to double bromodomain (dBD) (Audugé et al. 2019). Overall fluorescence lifetime varies with the change in condensation state of the chromatin both in vitro and in situ (Spagnol and Dahl 2016).

A fewer number of studies have utilized FLIM to investigate the structure and compaction state in mitotic chromosomes. These studies are mentioned below and summarized in Table 1. FLIM imaging has been used to study compaction of fixed methanol acetic acid chromosomes after staining with 4',6-diamidino-2phenylindole (DAPI) or Hoechst followed by lifetime measurements (Estandarte et al. 2016). Shorter lifetime was observed on heteromorphic chromosomes 1, 9, 15, 16 , and $\mathrm{Y}$ at the heterochromatic regions in comparison to other chromosomes in the human genome 


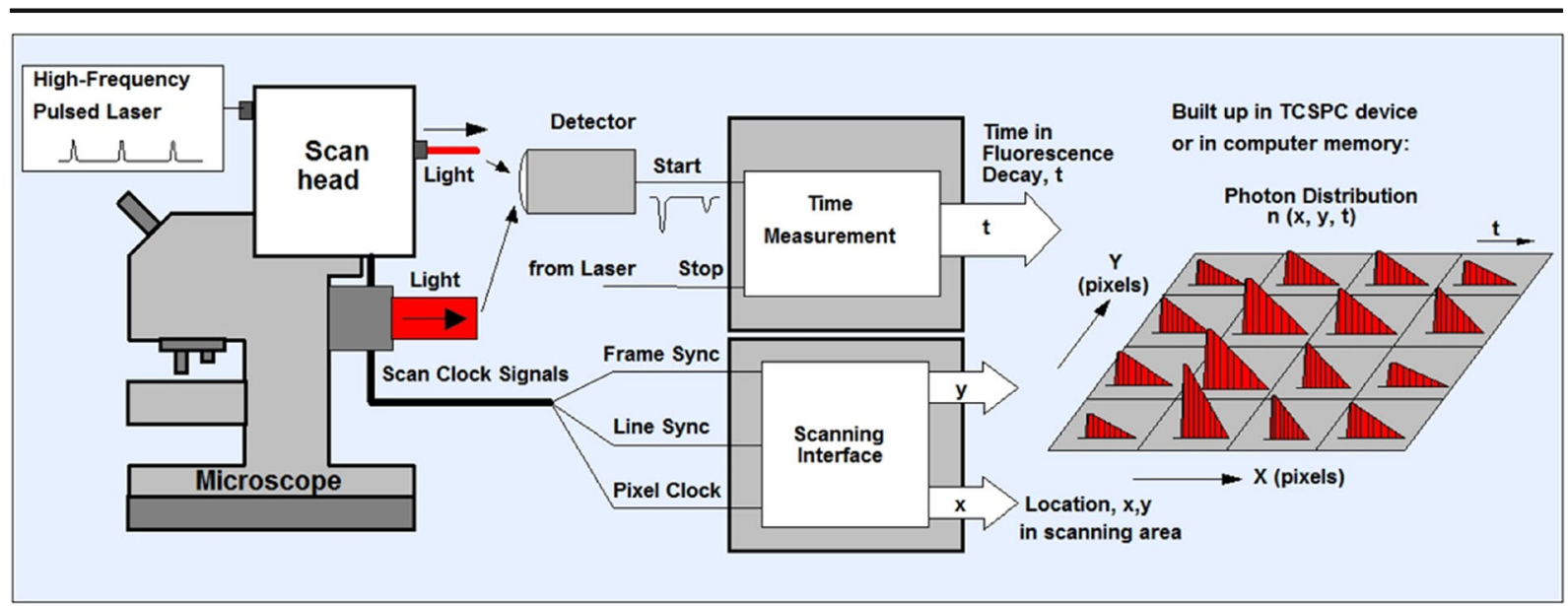

Fig. 2 Schematic of TCSPC-FLIM. The sample is scanned using a laser scanning microscope that has a focused beam of a highrepetition pulsed laser ion. The system can either be one or multiphoton depending on the laser used. The TCSPC detector attaches to either the confocal or non-descanned port of the microscope. The detector sends an electrical pulse into the TCSPC module upon detection of every photon. The TCSPC module (i)

(Estandarte et al. 2016) (Fig. 3). FLIM has been applied to quantitatively measure the number of G4 foci in metaphase chromosomes from number of cell lines showing that G4 structures are formed by human telomeric TTAGGG repeats on chromosomes (Tseng et al. 2020). FLIM-FRET in vivo has shown that the concentration of polyvalent cations and ATP levels affect chromatin conformation and compaction. ATP depletion was distinctive compared to the mitotic chromatin condensation (Visvanathan et al. 2013). Furthermore, the condensation process of chromosomes from prophase to prometaphase using calcium $\left(\mathrm{Ca}^{2+}\right)$ divalent cations in cells has been studied. This study demonstrated that $\mathrm{Ca}^{2+}$ plays a crucial role in the mitotic progression and condensation. $\mathrm{Ca}^{2+} \mathrm{de}-$ pleted chromosomes displayed fibrous structures whereas $\mathrm{CaCl}_{2}$-treated chromosomes displayed more compact globular structures (Phengchat et al. 2016). Chromatin compaction was measured during metaphase progression using FLIM-FRET whereby increase in compaction was observed from prometaphase to late anaphase that then decreased during telophase. Anaphase chromosomes also showed higher compaction at the chromosome arm edges during sister telomere separation, demonstrating the heterogeneity in chromatin compaction within individual chromosomes (Llères et al. 2009). determines the decay time ( $\mathrm{t}$ ) of the photon, (ii) receives scan clock signals (pixel, line, and frame clock) from the scan controller of the microscope, and also (iii) is configured as a scanning interface with 2 counters $\mathrm{X}, \mathrm{Y}$, for the $\mathrm{x}$ and $\mathrm{y}$ locations in the scanning area. (Reproduced with permission from W. Becker, The bh TCSPC handbook. 8th edition (2019) available on www.becker-hickl. com)

\section{Super-resolution microscopy}

Currently, there are a number of different approaches to improve the resolution of epifluorescence and confocal microscopes. The development of SRM techniques, such as point spread function (PSF) engineering, those that include structured illumination microscopy (SIM), 4Pi and stimulated emission depletion (STED), and single-molecule localization (SML) techniques including ground-state depletion microscopy followed by individual molecule return (GSDIM), photo-activated localization microscopy (PALM), and stochastic optical reconstruction microscopy (STORM), has been valuable to answer several biological questions (Galbraith and Galbraith 2011; Huang et al. 2009).

The principle of SML based super-resolution imaging and its different switching processes used for imaging are shown in Fig. 4. These myriads of superresolution development variants also offer the opportunity to image DNA and its higher-order structures such as chromosomes at almost $\times 10$ the resolution of confocal microscopes. These developments were awarded the 2014 Nobel Prize in Chemistry 2014 (Möckl et al. 2014). Recent development such as reversible saturable optical fluorescence transitions (RESOLFT and Minflux (MINimal photon 
Table 1 FLIM studies done on mitotic chromosomes

\begin{tabular}{|c|c|c|c|c|}
\hline $\begin{array}{l}\text { Microscopy } \\
\text { approach }\end{array}$ & Sample & Cell type & Findings & Publication \\
\hline FLIM & $\begin{array}{l}\text { Human fixed metaphase } \\
\text { chromosomes, DAPI and } \\
\text { Hoechst } 33258 \text { stained }\end{array}$ & $\begin{array}{l}\text { B-lymphocyte, HeLa, and } \\
\text { CCD37/LU }\end{array}$ & $\begin{array}{l}\text { Heteromorphic regions of chromosomes } 1,9, \\
15,16 \text {, and Y displayed shorter lifetimes } \\
\text { Variability in the lifetime amongst the } \\
\text { heteromorphic region is due to structural } \\
\text { changes }\end{array}$ & $\begin{array}{l}\text { Estandarte } \\
\text { et al. } 2016\end{array}$ \\
\hline FLIM & $\begin{array}{l}\text { Human fixed metaphase } \\
\text { chromosome and cells, } \\
\text { o-BMVC }\end{array}$ & $\begin{array}{l}\text { CL1-0, MRC-5, BJ, and } \\
\text { HeLa }\end{array}$ & $\begin{array}{l}\text { Anti-HT can unfold telomeric G4 structures in } \\
\text { fixed cells } \\
\text { Metaphase chromosomes possess G4 } \\
\text { structures formed by human telomeric } \\
\text { TTAGGG repeats }\end{array}$ & $\begin{array}{l}\text { Tseng et al. } \\
2020\end{array}$ \\
\hline FLIM-FRET & $\begin{array}{l}\text { Human live and permeabilized } \\
\text { mitotic cells, EGFP/mCherry }\end{array}$ & Hela & $\begin{array}{l}\text { Small molecules including cations and } \\
\text { polyamines influence the conformation and } \\
\text { compaction of chromatin within nuclei } \\
\text { Condensation upon ATP depletion in } \\
\text { interphase is distinctive from the mitotic } \\
\text { chromatin condensation }\end{array}$ & $\begin{array}{r}\text { Visvanathan } \\
\text { et al. } 2013\end{array}$ \\
\hline FLIM-FRET & $\begin{array}{l}\text { Human live cells and metaphase } \\
\text { chromosomes EGFP and } \\
\text { mCherry }\end{array}$ & $\begin{array}{l}\text { HeLa S3 cells, } \\
\text { HeLaH1.2-EGFP, } \\
\text { HeLaH2B-EGFP and } \\
\text { HeLaH2B-2Fp }\end{array}$ & $\begin{array}{l}\mathrm{Ca}^{2+} \text { plays a crucial role in the mitotic } \\
\text { progression and condensation of } \\
\text { chromosomes } \\
\mathrm{Ca}^{2+} \text {-depleted chromosomes showed fibrous } \\
\text { structure and } \mathrm{CaCl}_{2} \text {-treated chromosomes } \\
\text { had compact globular structure }\end{array}$ & $\begin{array}{l}\text { Phengchat } \\
\text { et al. } 2016\end{array}$ \\
\hline FLIM-FRET & $\begin{array}{l}\text { Human live cells interphase and } \\
\text { mitotic chromosomes, } \\
\text { H2B-EGFP, and } \\
\text { H2B-mCherry- }\end{array}$ & $\mathrm{HeLa}$ & $\begin{array}{l}\text { Chromatin compaction increases from } \\
\text { prometaphase to late anaphase and } \\
\text { decreases during telophase } \\
\text { Heterogeneity in chromatin within individual } \\
\text { chromosomes }\end{array}$ & $\begin{array}{l}\text { Llères et al. } \\
2009\end{array}$ \\
\hline
\end{tabular}

FLUXes)) has demonstrated a few nanometer resolutions (Xu and Liu 2019; Schermelleh et al. 2008).

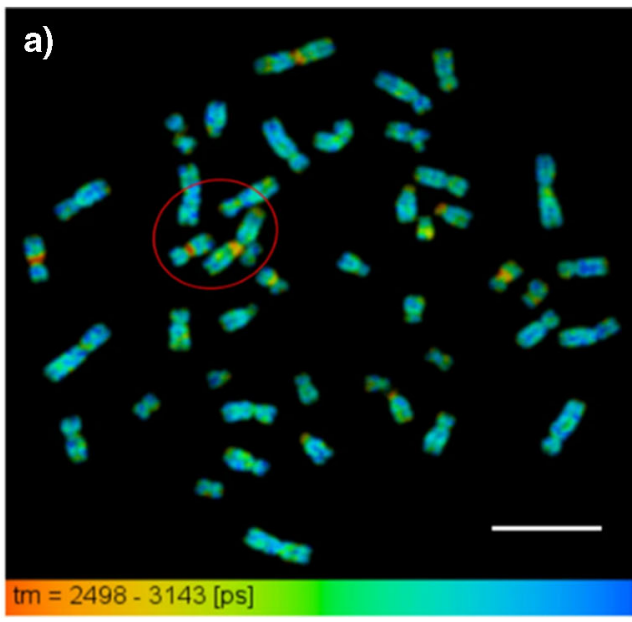

Fig. 3 FLIM on metaphase chromosomes. (a) Metaphase spread showing lifetime measurements on 46 human chromosomes (scale bar $=10 \mu \mathrm{m}$ ). (b) A zoomed-in image of circled area taken from (a) displaying variations in DAPI lifetime along the length of the
Of the PSF engineering (or hardware based), SIM and 3D-SIM offer the simplest route to improved resolution albeit by a factor of two (around $120 \mathrm{~nm}$ ). SIM is

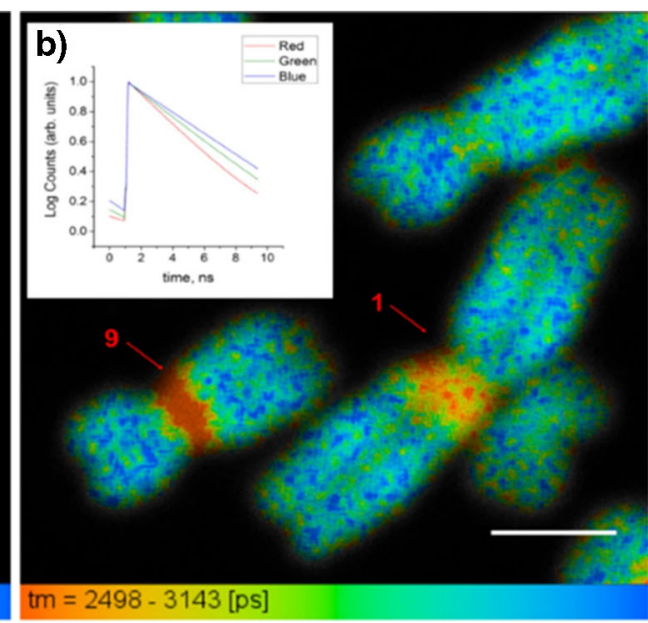

chromosomes 1 and 9 (scale bar $2 \mu \mathrm{m}$ ). The lifetime color range is from $2.50 \mathrm{~ns}$ (red) to $3.14 \mathrm{~ns}$ (blue). Fluorescence DAPI normalized curve shown at selected pixels from the red, green, and blue regions in chromosome 9. (Adapted from Estandarte et al. 2016) 
a wide-field FL microscopy technique that projects a grid pattern generated through interference of diffraction orders on the specimen (Fig. 5) (Gustafsson 2000). Three or more images with a set of rotations at a fixed angle, say $60^{\circ}$, are captured. A complex algorithm is then used to reconstruct the final image by extracting high-frequency components that contain the higher resolution information, which is otherwise lost in the standard wide-field imaging, as well as by the blurring from out-of-focus light contributions. No change in sample preparation is required for the SIM technique and so it can be applied to live cells. However, the technique can be relatively slow, several tens of seconds for $3 \mathrm{D}$, due to the need to acquire several images prior to computational analysis (Demmerle et al. 2017). It is worth noting that the technology is improving rapidly so that significant improvement in speed and real-time SIM is now possible. 3D-SIM has been applied to both DNA in cell nucleus and chromosome. In these initial studies, the chromatin surrounding a nuclear pore was observed.

STED has also been applied to image chromosomes with some success. The technique is light intensive and therefore not hugely suitable for live cell studies (Walther and Ellenberg 2018). In this technique, the PSF from a Gaussian beam, the transverse magnetic mode $\left(\mathrm{TM}_{00}\right)$, is shaped by the application of a second beam, the $\mathrm{TM}_{01}$ mode, that depletes the excited state of the molecules outside the zero intensity of the "donut" beam to achieve an improved diffraction-limited focus (d) (Fig. 6) (D'Abrantes et al. 2018). Hence, the $d$ in Eq. 1 is modified to Eq. 2.

$d=\frac{\lambda}{2 \mathrm{NA}}=\frac{\lambda}{2 n \sin \alpha}$

$$
\operatorname{STED} d=\frac{\lambda}{2 n \sin \alpha \sqrt{1+\frac{I}{I_{\mathrm{sat}}}}}
$$

Where $d$ is the diffraction limit, $\lambda$ is the excitation wavelength, NA is the numerical aperture or the refractive index $(n)$ of the medium multiplied by the sine of the angle of incidence, $\alpha, I$ is the intensity, and $I_{\text {sat }}$ is the depletion intensity.

Although STED is capable of producing superresolution images around $25 \mathrm{~nm}$, this significantly deteriorates when a $3 \mathrm{D}$ configuration is applied (around $70 \mathrm{~nm}$ in commercial systems). However, specialist STED systems are capable of achieving excellent z- resolution (Vicidomini et al. 2018). Furthermore, not all DNA labelling dyes can be used for STED microscopy. For example, the typical DAPI and Hoechst dyes do not undergo very good depletion processes and the high average depletion laser powers lead to multiphoton processes which degrade the image instead. Nonetheless, application of STED to chromosome studies using new and emerging dyes has shown the potential of the technique to chromatin and future chromosome studies (Kostiuk et al. 2019).

In the SML methods, PALM and STORM, GSDIM, have been valuable to answering several biological questions as well as applications towards chromosome research (Table 2). There are many "flavors" of SML which the reader is referred to in the review by Vangindertael et al. (2018). SML microscopies are capable of generating fluorescence images with resolutions around $10 \mathrm{~nm}$. These techniques require the use of chemicals that cycle between a metastable "dark" long-lived state generally via intersystem crossing to a triplet lower energy state and a fluorescent state. Removal of oxygen in the reaction environment ensures the extendedlifetime triplet state to allow the maximum singlemolecule photon emission (Fig. 7). This is required for the precise localization determination software used to generate the super-resolution image. A number of reports have shown that standard DNA staining dyes may be used for SML SRM, although better engineered dyes than DAPI or Hoechst generate better resolution, around the 10-nm region. Again due to the need to use toxic chemicals for SML microscopy, this technique is not ideal for live cell imaging. Furthermore, the extremely high average powers required at the sample $(>50 \mathrm{~mW})$ mean live cell studies are not recommended (Chen et al. 2014).

\section{Super-resolution microscopy for studying chromosome nanostructures}

SRM has been used for investigating interphase chromatin structures (Barth et al. 2020; Boettiger et al. 2016; Otterstrom et al. 2019; Ricci et al. 2015; Xu et al. 2020). SRM to a lesser extent has been explored for unravelling mitotic chromatin structures. These studies on mitotic chromosomes are summarized below and in Table 2 .

The use of STED showed enrichment of CAP-H2 (condensing II subunit) protein on the longitudinal 


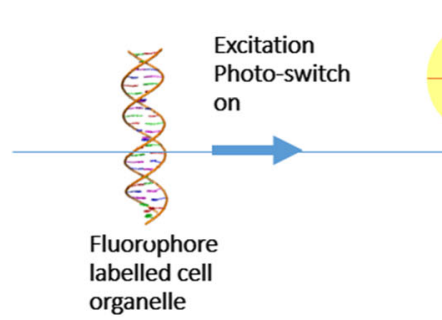

organelle

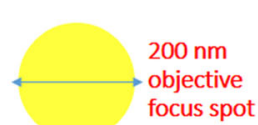

Fig. 4 Principle of single-molecule-localization-based superresolution imaging. A structure (e.g., DNA strand) below the diffraction-limit $(200 \mathrm{~nm})$ is densely labelled with photoswitchable chromophores. Single molecules are switched on sequentially, avoiding overlapping and imaged before being switched off. A new subset of individual molecules are switched

chromatid axis of chromosomes without extending to the surface of the chromosome (Walther and Ellenberg 2018) (Fig. 8a). SIM showed that chromosome scaffold consisted of proteins hCAP-E, Topo II $\alpha$, and KIF4 along the chromatid axes after immunostaining. Imaging of condensins and topoisomerase II $\alpha$ showed two main lateral strands that were twisted around each other within the chromatid axis (Fig. 8b). This study indicated that the assembly of these scaffold proteins and their compaction is crucial for maintaining the doublestranded chromosome scaffold structure (Poonperm et al. 2015). on, avoiding overlapping. When the fluorophores are imaged and their centroids precisely localized, spatial features of the structure are observed. The normally observed fluorescent image is indicated as a yellow circle whose center position is marked as a yellow "x"). An image is built up by repeatedly activating and localizing different molecules labelling the structure

Both SIM and STED have been used to investigate the linkages between ribosomal DNA on heterologous chromosomes. Fine filaments of chromatin were seen forming intrachromosomal linkages between sister chromatids and interchromosomal linkages between different acrocentric chromosomes, respectively. These filaments were consistently seen on numerous different human cell lines. A higher frequency of interchromosomal rDNA was observed in human iPS cells compared to their precursor HFF1 fibroblasts. These linkages increased with overexpression of c-Myc having a higher level of rRNA synthesis. Furthermore, UBF, a

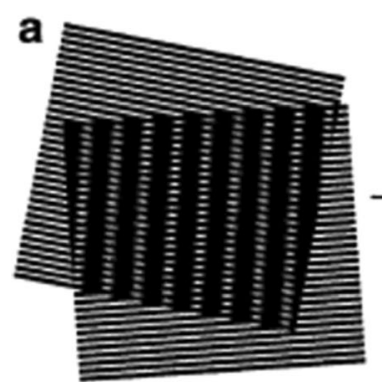

b

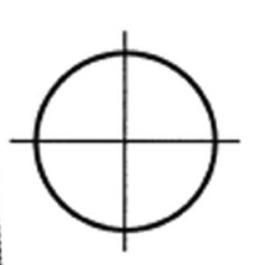

Fig. 5 Concept or resolution enhancement by structured illumination. (a) If two line patterns are superposed (multiplied), their product will contain moiré fringes (seen here as the apparent vertical stripes in the overlap region). (b) A conventional microscope is limited by diffraction. The set of low-resolution information that it can detect defines a circular "observable region" of reciprocal space. (c) A sinusoidally striped illumination pattern has only three Fourier components. The possible positions of the two side components are limited by the same circle that defines the observable region (dashed). If the sample is illuminated with such
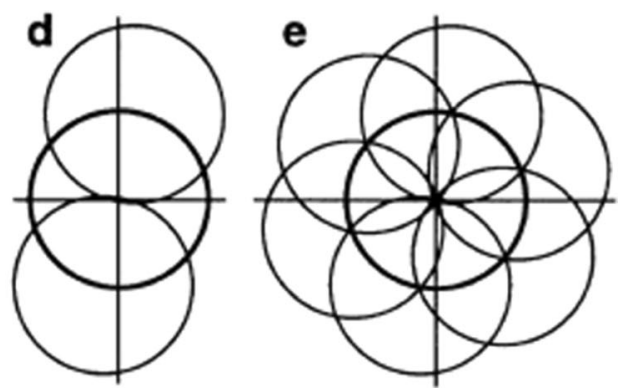

structured light, moiré fringes will appear which represent information that has changed position in reciprocal space. The amounts of the movement correspond to the three Fourier components of the illumination. The observable region will thus contain, in addition to the normal information, moved information that originates in two offset regions (d). From a sequence of such images with different orientation and phase of the pattern, it is possible to recover information from an area twice the size of the normally observable region, corresponding to twice the normal resolution (e). (Reproduced with permission from Gustafsson 2000) 


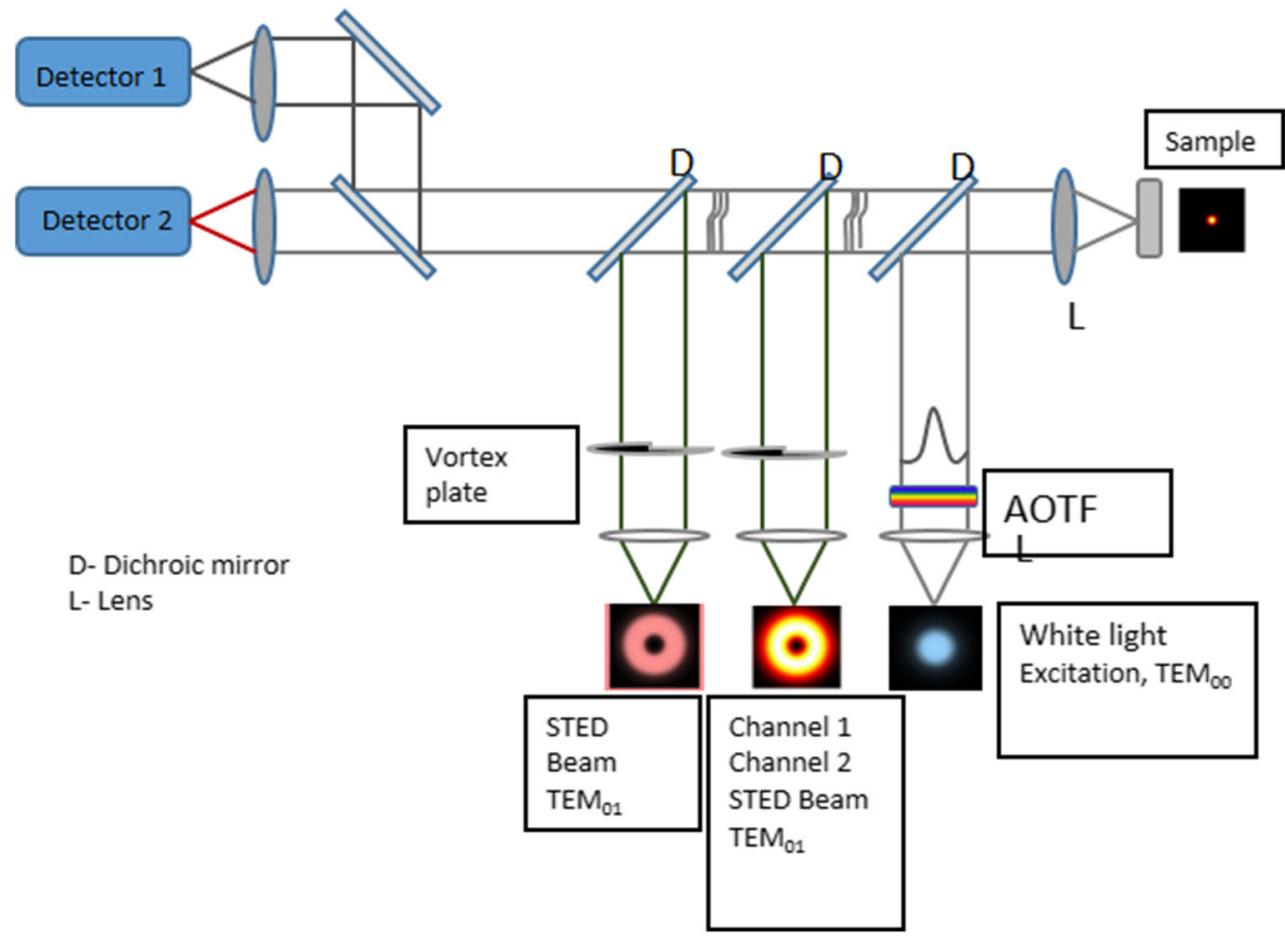

Fig. 6 Schematics of STED nanoscopy. (Reproduced with permission from D’Abrantes et al. 2018)

transcription factor that is associated with formation of rDNA linkages was consistently present on active loci throughout mitotic progression (Potapova et al. 2019) (Fig. 8c). Single-molecule photon localization microscopy (PLM) has been applied on an X-shaped chromosome that showed nucleotide density variations on chromatids. Metaphase chromosomes showed morphology similar to chromosomal fragile sites (Dong et al. 2016) (Fig. 8e).
PALM imaging of prometaphase/metaphase chromosomes with H2AvD-EGFP labelling showed 70$\mathrm{nm}$ (ranging from 40 to $90 \mathrm{~nm}$ ) structures composed of 35-nm stripes (Matsuda et al. 2010) (Fig. 8d). PALM imaging has also shown that nucleosomes form compact domains that are highly clustered during mitosis. Mitotic chromosomes in HeLa cells had a diameter of $\sim 140 \mathrm{~nm}$ similar to interphase domains. Indian muntjac chromosomes showed compact chromatin peak diameters

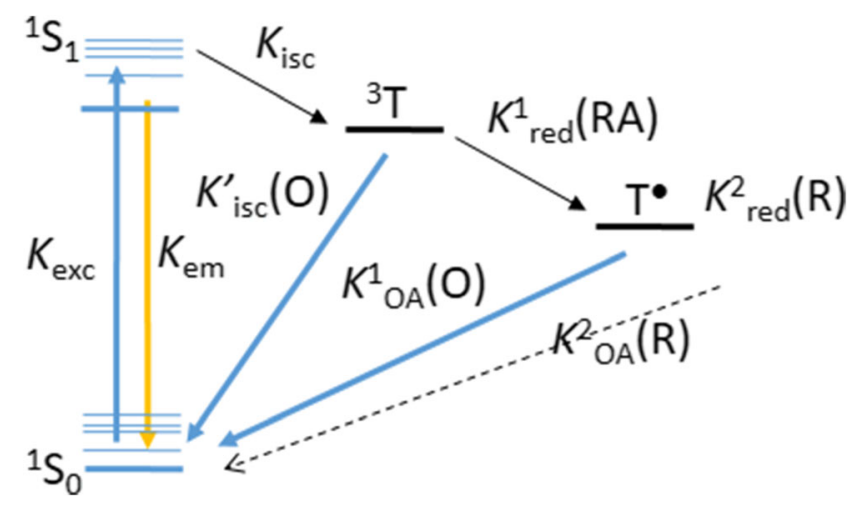

Fig. 7 Simplified Jablonski diagram of energy states for "blinking" molecules in SML microscopy. High-energy excited chromophore with a rake $k_{\text {exc }}$ is either cycled between its singlet ground (S1) and excited state, ${ }^{1} \mathrm{~S}_{1}$, emitting lower fluorescence photons with a rate of $k_{\mathrm{em}}$ or can undergo intersystem crossing to the triplet state ${ }^{3} \mathrm{~T}$ with rate $k_{\text {isc }}$ upon irradiation. The triplet state $\left({ }^{3} \mathrm{~T}\right)$ can react with an oxidizing agent, e.g., molecular oxygen and reducing agent (RA) before recycling 


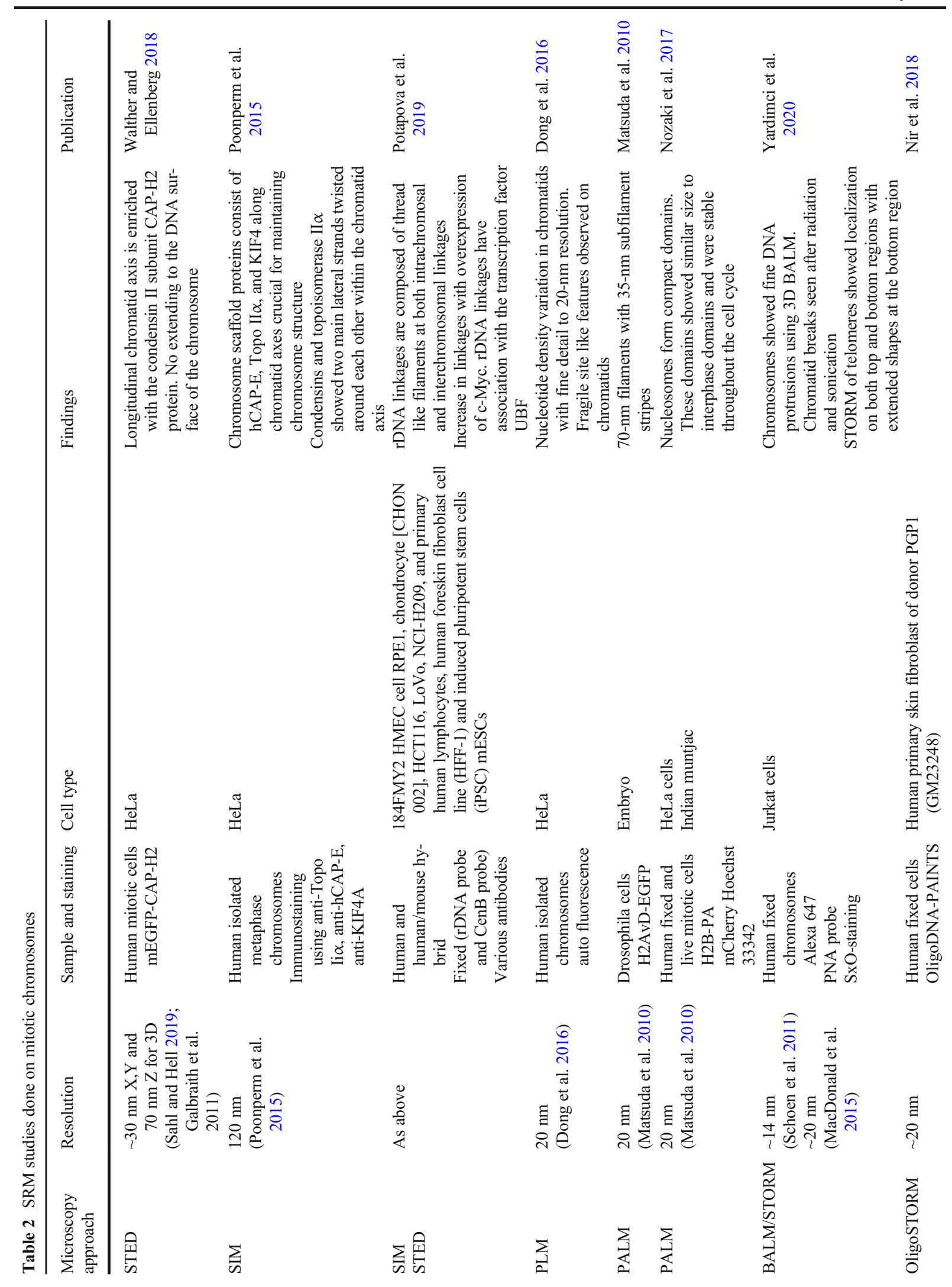




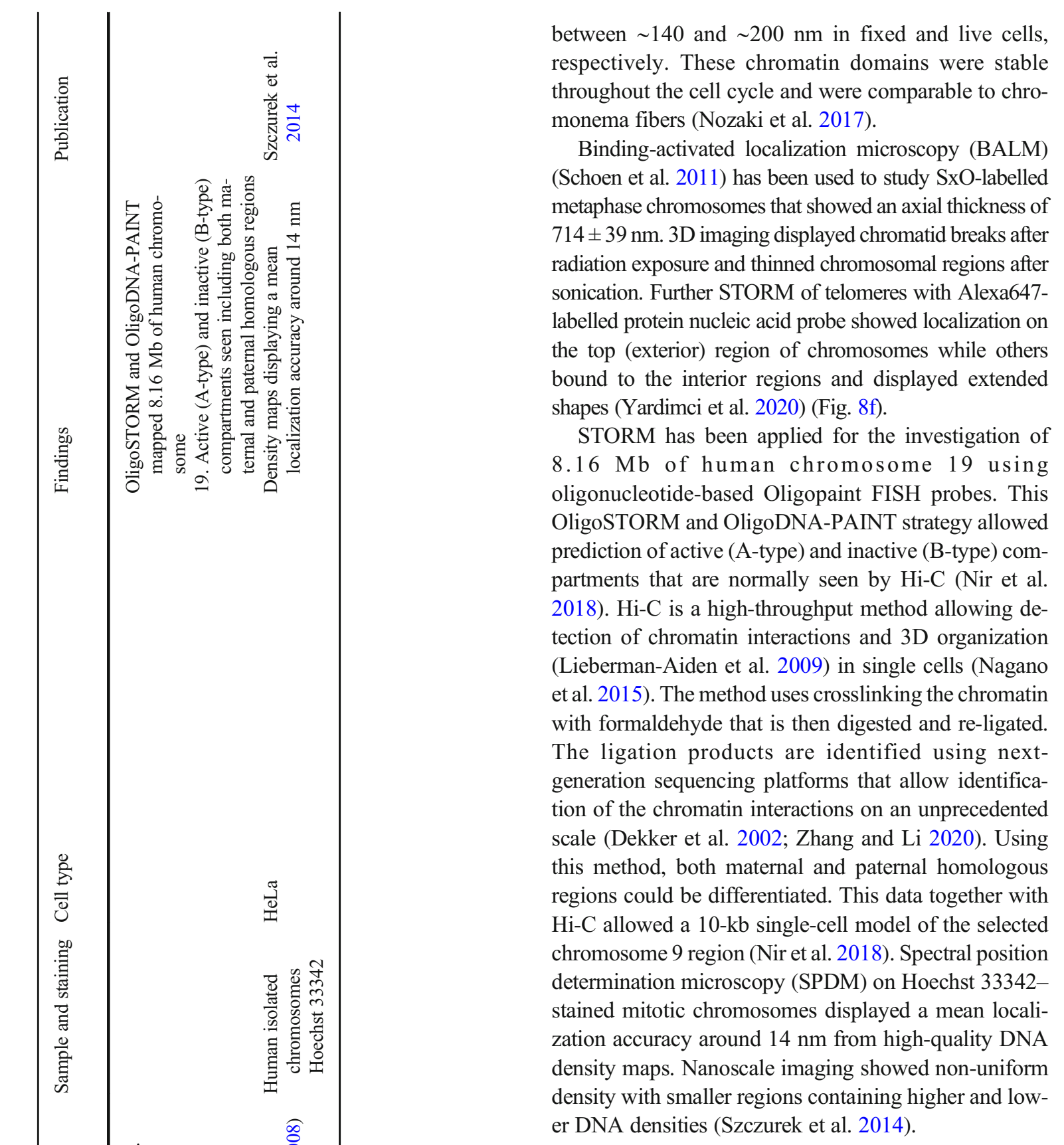

Future prospects

Both FL microscopy techniques, FLIM and SRM, are beginning to be extremely useful for the understanding of mitotic chromosome structure and condensation of chromosomes. This is an emerging field moving at a rapid pace. We have discussed examples where their use for chromatin research has significant advantages over 

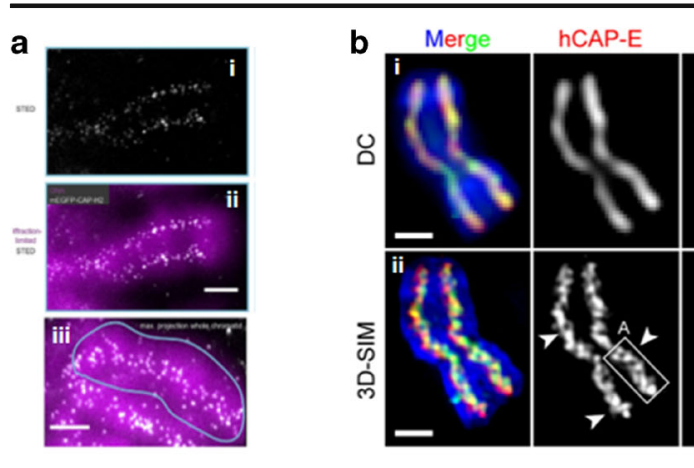

e

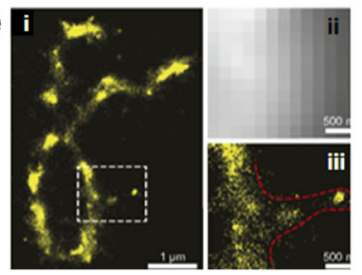

f $\mathbf{i}$

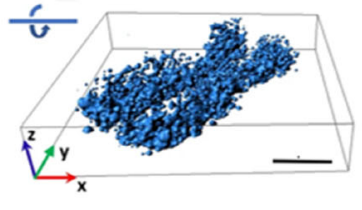

Fig. 8 Imaging of mitotic chromosomes using different SRM approaches. (a) STED imaging of a mitotic chromosome. (i) STED image of a mEGFP-CAPH2-labelled chromosome. (ii) An overlay image with the diffraction-limited chromatids (magenta). STED imaging resolved mEGFP-CAP_H2 to distinguishable single spots within the central longitudinal axis of both prometaphase chromatids. (iii) Maximum projection of the combined DNA (magenta) and mEGFP-CAP-H2 (white) showing chromatid outlined in cyan. Scale bars, $1 \mu \mathrm{m}$ (reproduced with permission from Walther and Ellenberg 2018). (b) 3D mapping of hCAP-E and Topo II $\alpha$ scaffold proteins on HeLa-wt metaphase chromosomes. (i) Deconvolution (DC) microscopy of immunostained chromosome where the two scaffold proteins could not be solved. (ii) 3D-SIM showing improved resolution images of the same chromosome as (i). Arrowheads show double strands. DNA is shown in blue. Scale bars for (i) and (ii), $1 \mu \mathrm{m}$. The insets A and B show magnified views of the white boxes in (ii) as indicated with red dotted lines indicating double strands of chromosome scaffold. Scale bar for insets A and B, $202 \mathrm{~nm}$ (reproduced with permission from Poonperm et al. 2015). (c) SIM of rDNA-linked mitotic chromosomes. (i) cMyc-3 labelled using immuno-FISH

other imaging methods such as X-rays and cryo-electron microscopy with less than $100 \mathrm{~nm}$ resolution. The SRM methods discussed here are powerful and have provided precise quantitative information into fixed samples. Although data on live chromosomes samples are limited, SRM has the capability to overcome this. However, more comprehensive and integrative approaches are needed to further understand the mechanisms underlying the complex dynamic properties of chromatin.

One of the major interest surrounding chromosome studies is to resolve the $30-\mathrm{nm}$ chromatin structure that remains controversial (Maeshima et al. 2010; Nishino et al. 2012; Fussner et al. 2011). Microscopy efforts

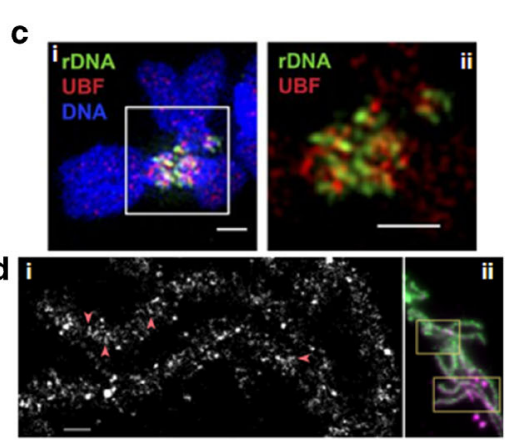

ii

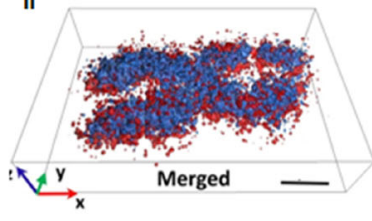

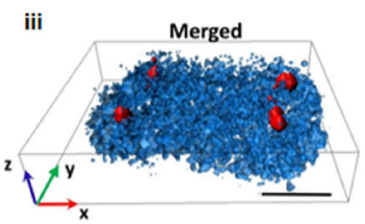

with rDNA probe (green) and UBF antibody (red). Both rDNA and UBF form filamentous connections between chromosomes. (ii) Zoomed-in view of white box in (i). Scale bars, $1 \mu \mathrm{m}$ (reproduced with permission from Potapova et al. 2019). (d) PALM imaging of chromosome arms. (ii) Wide-field image of chromosomes, DAPI staining is shown in purple and H2AvDEGFP is shown in green. Scale bars for (i) $0.5 \mu \mathrm{m}$ and for (ii), $3 \mu \mathrm{m}$ (reproduced with permission from Matsuda et al. 2010). (e) PLM imaging of a chromosome. (i) X-shaped chromosome after PLM imaging, (ii) unresolved wide-field fluorescence image, (iii) DNA-PLM image of the squared region in (i) showing additional fine features which are not resolvable in wide-field image (reproduced with permission from Dong et al. 2016). (f) 3D BALM images of metaphase chromosome. (i) Undamaged chromosome and (ii) irradiated chromosome with a groove on one of the arms (red shows lower and blue shows upper layer of 3D surface plots). (iii) 3D image of telomeric regions of a mitotic chromosome with merged surface plots of BALM (blue) and STORM (red). Scale bars, $1 \mu \mathrm{m}$ (reproduced with permission from Yardimci et al. 2020)

have already been in applying electrons (Eltsov et al. 2014; Robinson et al. 2006; Fukui 2016; Ou et al. 2017) and X-rays using SAXs (Joti et al. 2012; Nishino et al. 2012) and imaging (Yan et al. 2016; Nishino et al. 2009) for unravelling chromatin structure. Chromatin compaction states during metaphase in different cell types is yet to be examined whereby FLIM and SRM can be applied. This would require investigation into the structure/compaction of DNA together with specific protein labelling of histones (DNA-histone and histone-histone interactions), scaffold and structural proteins that will provide the nanoscale architecture of mitotic chromosomes. Considering FLIM can be 
applied to live samples to study both DNA and proteins, the combination of SRM and FLIM offers an opportunity to investigate chromosome structure in live cell. This is currently not possible using electrons or X-rays.

FLIM in particular has been little explored for chromosome research. High-resolution or super-resolution FLIM, i.e., when combined with other SRM methods such as STED-FLIM, may be a useful way forward in order to obtain more precise chromatin measurements below $50 \mathrm{~nm}$. New and emerging PSF engineering SRM such as RESOLFT and MinFlux (MINimal photon FLUXes) (Schermelleh et al. 2019) that have demonstrated a few nanometer resolutions may also be combined with FLIM to obtain information around the immediate environment of the chromatin in live cells. Although the excited state lifetime of a molecule is not affected by concentration and bleaching, it is sensitive to the environment such as changes in $\mathrm{pH}$, viscosity, and the presence of other molecules (Berezin and Achilefu 2010). In particular, these three techniques may allow super resolution towards imaging chromosomes inside intact cells below $30 \mathrm{~nm}$. The development of super-resolution 3DFLIM will also allow imaging of the full sample volume. High-resolution FLIM-FRET imaging may also be highly beneficial to map a larger number of chromosomal structural and scaffold proteins and their structure/ function relationship. Cryogenic SRM using STORM is beginning to allow high-resolution imaging to resolution below $12 \mathrm{~nm}$. This has been recently demonstrated on bacterial cells and is yet to be explored on chromosomes (Bateman et al. 2019; Wang et al. 2019). Furthermore, fluorescent proteins have been used to obtain superresolution registration accuracy of around $10 \mathrm{~nm}$ (Tuijtel et al. 2019), and this is ideal for imaging the currently known substructures of chromosomes.

We are now witnessing new methods that can provide detailed structural information into chromatin. Expansion microscopy using SRM has provided an improved resolution by enlargement of small structures in an isotropic manner thereby preserving the ultrastructure of the samples in 3D. This method has been applied to study tissue specimens from various species (Chen et al. 2015; Götz et al. 2020; Freifeld et al. 2017; Truckenbrodt et al. 2019), subcellular structures including synaptonemal complex protein components (Cahoon et al. 2017), and centrioles (Zwettler et al. 2020). Expansion microscopy using SIM has allowed visualization of chromatin structure at up to $25-35 \mathrm{~nm}$ in Barley nuclei (Kubalová et al. 2020). However, the potential of this method has not yet fully explored on mitotic chromosomes. Specific labelling of proteins and DNA sequences on spatially expanded chromosomes will enable the determination of chromatin ultrastructure-function dynamics (Kubalová et al. 2020).

New developments in (i) staining/labelling strategies of chromatin; (ii) microscope optics with improved detectors, light sources, filters, and objective lenses; and (iii) data analysis software will undoubtedly provide unanticipated insights into imaging and quantitative analysis of chromosomes. FL microscopy has continued to advance mostly through new labelling techniques (dyes and GFP) as well as improvements in detection sensitivity. These two components are still the main bottle neck and therefore represent opportunities for future improvements for SRM towards chromosome research. Another technology that is likely to be important in chromosome research is the CRISPR/Cas 9 technology that was awarded the 2020 Nobel Prize (Strzyz 2020). Here both the DNA proteins and DNA itself may be manipulated to generate structures that could be imaged under super-resolution condition. This technology in particular has the potential to make imaging chromosomes in live cells possible as demonstrated by Zhou et al. (2017).

In this review article, we have not commented on FL microscopy techniques that provide resolution around $140 \mathrm{~nm}$ such as AiryScan (hardware), HyVolution, and Super-resolution radial fluctuations (SRRF) (software) (Culley et al. 2018). These "halfway house" techniques, which there are many, may have increment usage in chromosome research but somewhat limited currently. However, these techniques do not require any special sample treatment and are likely to be useful for live cell chromosome studies.

Altogether, sample choice either being fixed or live will have to be carefully considered for future studies in fundamental processes that accompany physiological and pathological changes in chromosomes. In both tissues and cell lines, differences in nucleosome positions in disease states have been identified (Valouev et al. 2011) highlighting that the chromatin structure is crucial for correct genome function (Misteli 2010). The nanoscale structural modifications remain largely unknown where both SRM and FLIM offer huge potential in the future.

SRM has already been applied to understand chromatin structures in different diseased states such as cancer samples (Wang et al. 2014; Xu et al. 2018; Xu 
et al. 2020) and neurodegenerative disorders (Frost et al. 2016). Furthermore, SRM could also be used to identify the role of different structural proteins in altering the chromatin structure during cardiac disease states (Mitchell-Jordan et al. 2012). This has also been explored using FLIM for investigating heterogeneity in tumor chromatin and to examine the influence of drug targeting on chromatin changes (Sparks et al. 2018). Ultimately it will be useful to make workflows for the use of SRM and FLIM for clinical medicine applications, mainly for the diagnosis of diseases that would assist in understanding different disease states such as cancer and developmental and genetic disorders.

\section{Conclusion}

Both FLIM and SRM are serving as useful approaches for providing nanoscale information into mitotic chromosome structure and its compaction. No doubt these FL imaging methods together with different labelling strategies and integration with other modalities will solve the long-standing chromosome mysteries including the controversial 30-nm structure. In this review, we have provided information about several superresolution techniques that are likely to be crucial in imaging chromosomes at the tens of nanometer scale (nanoscopy). We finally propose the combination of FLIM and SRM as a logical step in FL microscopy development for chromosome research to bridge the gap between structure provided by super-resolution imaging or crystallography (current high resolution provided by X-rays and electron) and function (normally provided by live cell FL microscopy). FLIM also offers further advantages and information about the molecular or chromophore environment that steady-state FL alone is unable to provide.

Abbreviations $B A L M$, Binding-Activated Localization Microscopy; DAPI, 4',6-diamidino-2-phenylindole; $E d U$, 5Ethynl-2'-deoxyuridine; FLIM, Fluorescence Lifetime Imaging Microscopy; FRET, Forster Resonance Energy Transfer; ICCD, Intensified Charged Coupled Device; MinFlux, MINimal photo FLUXes; PALM, Photo-Activated Localization Microscopy; PSF, Point Spread Function; SEM, Scanning Electron Microscopy; SIM, Structured Illumination Microscopy; SML, Single Molecule Localization; $S R M$, Super Resolution Microscopy; SRRF, Super-
Resolution Radial Fluctuations; STED, Stimulated Emission Depletion; STORM, Stochastic Optical Reconstruction Microscopy; TCSPC, Time-Correlated Single-Photon Counting

Funding This study was supported by the UK BBSRC (BB/ H022597/1) grant "Professorial Fellowship for imaging chromosomes by coherent X-ray diffraction". Others include the Brookhaven National Laboratory supported by the U.S. Department of Energy, Office of Science, Office of Basic Energy Sciences, under Contract No. DE-SC0012704. Financial support was also provided by Professor El-Nasir Lalani at the Aga Khan University and generous donors.

Open Access This article is licensed under a Creative Commons Attribution 4.0 International License, which permits use, sharing, adaptation, distribution and reproduction in any medium or format, as long as you give appropriate credit to the original author(s) and the source, provide a link to the Creative Commons licence, and indicate if changes were made. The images or other third party material in this article are included in the article's Creative Commons licence, unless indicated otherwise in a credit line to the material. If material is not included in the article's Creative Commons licence and your intended use is not permitted by statutory regulation or exceeds the permitted use, you will need to obtain permission directly from the copyright holder. To view a copy of this licence, visit http://creativecommons.org/licenses/by/4.0/.

\section{References}

Abbe E (1873) Beiträge zur Theorie des Mikroskops und der mikroskopischen Wahrnehmung. Arch Mikrosk Anat 9(1): 413-468

Abdollahi E, Taucher-Scholz G, Jakob B (2018) Application of fluorescence lifetime imaging microscopy of DNA binding dyes to assess radiation-induced chromatin compaction changes. International journal of molecular sciences 19(8): 2399 (3)

Audugé N, Padilla-Parra S, Tramier M, Borghi N, Coppey-Moisan M (2019) Chromatin condensation fluctuations rather than steady-state predict chromatin accessibility. Nucleic acids research 47(12):6184-6194 (13)

Bacskai BJ, Skoch J, Hickey GA, Allen R, Hyman BT (2003) Fluorescence resonance energy transfer determinations using multiphoton fluorescence lifetime imaging microscopy to characterize amyloid-beta plaques. J Biomed Opt 8(3):368376

Balchand SK, Mann BJ, Wadsworth P (2016) Using fluorescence microscopy to study mitosis. In: The Mitotic Spindle. Humana Press, New York, NY, pp 3-14

Barth R, Bystricky K, Shaban H (2020) Coupling chromatin structure and dynamics by live super-resolution imaging. bioRxiv:777482

Bateman BC, Zanetti-Domingues LC, Moores AN, Needham SR, Rolfe DJ, Wang L, Clarke DT, Martin-Fernandez ML (2019) 
Super-resolution microscopy at cryogenic temperatures using solid immersion lenses. Bio-protocol 9(22):e3426

Becker W. The bh TCSPC handbook. 8th edition (2019) available on www.becker-hickl.com

Belmont AS (2001) Visualizing chromosome dynamics with GFP. Trends Cell Biol 11(6):250-257

Bendandi A, Dante S, Zia SR, Diaspro A, Rocchia W (2020) Chromatin compaction multiscale modeling: a complex synergy between theory, simulation, and experiment. Front Mol Biosci 7:15

Berezin MY, Achilefu S (2010) Fluorescence lifetime measurements and biological imaging. Chem Rev 110(5):2641-2684

Boettiger AN, Bintu B, Moffitt JR, Wang S, Beliveau BJ, Fudenberg G, Imakaev M, Mirny LA, Wu CT, Zhuang X (2016) Super-resolution imaging reveals distinct chromatin folding for different epigenetic states. Nature 529(7586): 418-422

Botchway (n.d.) Presented at the UK_Japan XY chromosome workshop May 2015, Bangkok)

Botchway SW, Scherer KM, Hook S, Stubbs CD, Weston E, Bisby RH, Parker AW (2015) A series of flexible design adaptations to the Nikon E-C1 and E-C2 confocal microscope systems for UV, multiphoton and FLIM imaging. J Microsc 258(1):68-78

Boveri T (1909) Die Blastomerenkerne von Ascaris megalocephala und die Theorie der Chromosomenindividualität. Wilhelm Engelmann, Leipzig

Cahoon CK, Yu Z, Wang Y, Guo F, Unruh JR, Slaughter BD, Hawley RS (2017) Superresolution expansion microscopy reveals the three-dimensional organization of the Drosophila synaptonemal complex. Proc Natl Acad Sci 114(33):E6857-E6866

Chen BC, Legant WR, Wang K, Shao L, Milkie DE, Davidson MW et al (2014) Lattice light-sheet microscopy: imaging molecules to embryos at high spatiotemporal resolution. Science 346(6208): 1257998

Chen F, Tillberg PW, Boyden ES (2015) Expansion microscopy. Science 347(6221):543-548

Chen B, Yusuf M, Hashimoto T, Estandarte AK, Thompson G, Robinson I (2017) Three-dimensional positioning and structure of chromosomes in a human prophase nucleus. Sci Adv 3(7):e1602231

Cremer T, Cremer M (2010) Chromosome territories. Cold Spring Harb Perspect Biol 2(3):a003889

Culley S, Tosheva KL, Pereira PM, Henriques R (2018) SRRF: universal live-cell super-resolution microscopy. Int $\mathrm{J}$ Biochem Cell Biol 101:74-79

D'Abrantes S, Gratton S, Reynolds P, Kriechbaumer V, McKenna J, Barnard S, Clarke DT, Botchway SW (2018) Superresolution nanoscopy imaging applied to DNA doublestrand breaks. Radiat Res 189(1):19-31

Davey CA, Sargent DF, Luger K, Maeder AW, Richmond TJ (2002) Solvent mediated interactions in the structure of the nucleosome core particle at $1.9 \AA$ resolution. J Mol Biol 319(5):1097-1113

Dekker J, Rippe K, Dekker M, Kleckner N (2002) Capturing chromosome conformation. Science 295(5558):1306-1311

Demmerle J, Innocent C, North AJ, Ball G, Müller M, Miron E, Matsuda A, Dobbie IM, Markaki Y, Schermelleh L (2017) Strategic and practical guidelines for successful structured illumination microscopy. Nat Protoc 12(5):988-1010
Dong B, Almassalha LM, Stypula-Cyrus Y, Urban BE, Chandler JE, Sun C et al (2016) Superresolution intrinsic fluorescence imaging of chromatin utilizing native, unmodified nucleic acids for contrast. Proc Natl Acad Sci 113(35):9716-9721

Eltsov M, Sosnovski S, Olins AL, Olins DE (2014) ELCS in ice: cryo-electron microscopy of nuclear envelope-limited chromatin sheets. Chromosoma 123(3):303-312

Estandarte AK, Botchway S, Lynch C, Yusuf M, Robinson I (2016) The use of DAPI fluorescence lifetime imaging for investigating chromatin condensation in human chromosomes. Sci Rep 6:31417

Flors C, Earnshaw WC (2011) Super-resolution fluorescence microscopy as a tool to study the nanoscale organization of chromosomes. Curr Opin Chem Biol 15(6):838-844

Ford CE, Jones KW, Polani PE, De Almeida JC, Briggs JH (1959). A sex-chromosome anomaly in a case of gonadal dysgenesis (Turner's syndrome)

Freifeld L, Odstrcil I, Förster D, Ramirez A, Gagnon JA, Randlett O et al (2017) Expansion microscopy of zebrafish for neuroscience and developmental biology studies. Proc Natl Acad Sci 114(50):E10799-E10808

Frost B, Bardai FH, Feany MB (2016) Lamin dysfunction mediates neurodegeneration in tauopathies. Curr Biol 26(1):129136

Fukui K (2016) Contribution of nanotechnology to chromosome science. Chromosome Science 19(1-4):51-56

Fussner E, Ching RW, Bazett-Jones DP (2011) Living without $30 \mathrm{~nm}$ chromatin fibers. Trends Biochem Sci 36(1):1-6

Galbraith CG, Galbraith JA (2011) Super-resolution microscopy at a glance. J Cell Sci 124(10):1607-1611

Görlitz, F., Corcoran, D. S., Garcia Castano, E. A., Leitinger, B., Neil, M. A., Dunsby, C., \& French, P. M. (2017, September). Mapping molecular function to biological nanostructure: combining structured illumination microscopy with fluorescence lifetime imaging (SIM+ FLIM). In Photonics (Vol. 4, No. 3, p. 40). Multidisciplinary Digital Publishing Institute

Götz R, Panzer S, Trinks N, Eilts J, Wagener J, Turrà D, di Pietro A, Sauer M, Terpitz U (2020) Expansion microscopy for cell biology analysis in fungi. Front Microbiol 11:574

Gustafsson MG (2000) Surpassing the lateral resolution limit by a factor of two using structured illumination microscopy. J Microsc 198(2):82-87

Hinde E, Cardarelli F, Chen A, Khine M, Gratton E (2012) Tracking the mechanical dynamics of human embryonic stem cell chromatin. Epigenetics \& chromatin 5(1):1-11 (17)

Hockings C, Poudel C, Feeney KA, Novo CL, Hamouda MS, Mela I et al (2020) Illuminating chromatin compaction in live cells and fixed tissues using SiR-DNA fluorescence lifetime. bioRxiv (6)

Holmquist GP, Ashley T (2006) Chromosome organization and chromatin modification: influence on genome function and evolution. Cytogenetic and genome research 114(2):96-125

Huang B, Bates M, Zhuang X (2009) Super-resolution fluorescence microscopy. Annu Rev Biochem 78:993-1016

Inaga S, Tanaka K, Ushiki T (2008) Transmission and scanning electron microscopy of mammalian metaphase chromosomes. In: Chromosome nanoscience and technology. CRC Press, Boca Raton, pp 93-104

Ishizuka T, Liu HS, Ito K, Xu Y (2016) Fluorescence imaging of chromosomal DNA using click chemistry. Sci Rep 6(1):1-10 
Jacobs PA, Strong JA (1959) A case of human intersexuality having a possible XXY sex-determining mechanism. Nature 183(4657):302-303

Jacobs P, Baikie AG, MacGregor TN, Maclean N, Harnden DG (1959) Evidence for the existence of the human "super female". Lancet 274(7100):423-425

Joti Y, Hikima T, Nishino Y, Kamada F, Hihara S, Takata H, Ishikawa T, Maeshima K (2012) Chromosomes without a 30$\mathrm{nm}$ chromatin fiber. Nucleus 3(5):404-410

Kanda T, Sullivan KF, Wahl GM (1998) Histone-GFP fusion protein enables sensitive analysis of chromosome dynamics in living mammalian cells. Curr Biol 8(7):377-385

Kostiuk G, Bucevičius J, Gerasimaite R, Lukinavičius G (2019) Application of STED imaging for chromatin studies. J Phys D Appl Phys 52(50):504003

Krietenstein N, Rando OJ (2020) Mesoscale organization of the chromatin fiber. Curr Opin Genet Dev 61:32-36

Kubalová I, Schmidt Černohorská M, Huranová M, Weisshart K, Houben A, Schubert V (2020) Prospects and limitations of expansion microscopy in chromatin ultrastructure determination. Chromosome research : an international journal on the molecular, supramolecular and evolutionary aspects of chromosome biology 28(3-4):355-368

Lakowicz JR (2006) Principles of fluorescence spectroscopy, 3rd edn. Springer, New York, 954 pp

Lejeune J (1959) Etude des chromosomes somatiques de neuf enfants mongoliens. CR Acad Sci Paris 248:1721-1722

Lemmer P, Gunkel M, Baddeley D, Kaufmann R, Urich A, Weiland Y, Reymann J, Müller P, Hausmann M, Cremer C (2008) SPDM: light microscopy with single-molecule resolution at the nanoscale. Applied Physics B 93(1):1-12

Lesoine MD, Bose S, Petrich JW, Smith EA (2012) Supercontinuum stimulated emission depletion fluorescence lifetime imaging. J Phys Chem B 116(27):7821-7826

Levsky JM, Singer RH (2003) Fluorescence in situ hybridization: past, present and future. J Cell Sci 116(14):2833-2838

Lieberman-Aiden E, Van Berkum NL, Williams L, Imakaev M, Ragoczy T, Telling A et al (2009) Comprehensive mapping of long-range interactions reveals folding principles of the human genome. Science 326(5950):289-293

Lipinski DM, Yusuf M, Barnard AR, Damant C, Issa PC, Singh MS, Lee E, Davies WL, Volpi EV, MacLaren RE (2011) Characterization of a dominant cone degeneration in a green fluorescent protein-reporter mouse with disruption of loci associated with human dominant retinal dystrophy. Invest Ophthalmol Vis Sci 52(9):6617-6623

Llères D, James J, Swift S, Norman DG, Lamond AI (2009) Quantitative analysis of chromatin compaction in living cells using FLIM-FRET. J Cell Biol 187(4):481-496

Lou J, Scipioni L, Wright BK, Bartolec TK, Zhang J, Masamsetti VP et al (2019) Phasor histone FLIM-FRET microscopy quantifies spatiotemporal rearrangement of chromatin architecture during the DNA damage response. Proceedings of the National Academy of Sciences 116(15):7323-7332 14

Luger K, Mäder AW, Richmond RK, Sargent DF, Richmond TJ (1997) Crystal structure of the nucleosome core particle at 2.8 Å resolution. Nature 389(6648):251-260

Ma H, Naseri A, Reyes-Gutierrez P, Wolfe SA, Zhang S, Pederson $\mathrm{T}$ (2015) Multicolor CRISPR labeling of chromosomal loci in human cells. Proc Natl Acad Sci 112(10):3002-3007
MacDonald L, Baldini G, Storrie B (2015) Does super-resolution fluorescence microscopy obsolete previous microscopic approaches to protein co-localization? Methods in molecular biology (Clifton, N.J.) 1270:255-275

Maeshima K, Hihara S, Eltsov M (2010) Chromatin structure: does the 30-nm fibre exist in vivo? Curr Opin Cell Biol 22: 291-297

Maeshima K, Imai R, Tamura S, Nozaki T (2014) Chromatin as dynamic 10-nm fibers. Chromosoma 123(3):225-237

Maeshima K, Ide S, Hibino K, Sasai M (2016) Liquid-like behavior of chromatin. Curr Opin Genet Dev 37:36-45

Matsuda A, Shao L, Boulanger J, Kervrann C, Carlton PM, Kner P, Agard D, Sedat JW (2010) Condensed mitotic chromosome structure at nanometer resolution using PALM and EGFP-histones. PLoS One 5(9):e12768

Misteli T (2010) Higher-order genome organization in human disease. Cold Spring Harb Perspect Biol 2(8):a000794

Mitchell-Jordan S, Chen H, Franklin S, Stefani E, Bentolila LA, Vondriska TM (2012) Features of endogenous cardiomyocyte chromatin revealed by super-resolution STED microscopy. J Mol Cell Cardiol 53(4):552-558

Möckl L, Lamb DC, Bräuchle C (2014) Super-resolved fluorescence microscopy: Nobel Prize in Chemistry 2014 for Eric Betzig, Stefan Hell, and William E. Moerner Angewandte Chemie International Edition 53(51):13972-13977

Murata SI, Herman P, Lin HJ, Lakowicz JR (2000) Fluorescence lifetime imaging of nuclear DNA: effect of fluorescence resonance energy transfer. Cytometry: The Journal of the International Society for Analytical Cytology 41(3):178$185(8)$

Murata SI, Herman P, Lakowicz JR (2001) Texture analysis of fluorescence lifetime images of AT-and GC-rich regions in nuclei. Journal of Histochemistry \& Cytochemistry 49(11): 1443-1451 (12)

Nagano T, Lubling Y, Yaffe E, Wingett SW, Dean W, Tanay A, Fraser P (2015) Single-cell Hi-C for genome-wide detection of chromatin interactions that occur simultaneously in a single cell. Nat Protoc 10(12):1986-2003

Nir G, Farabella I, Estrada CP, Ebeling CG, Beliveau BJ, Sasaki $\mathrm{HM}$ et al (2018) Walking along chromosomes with superresolution imaging, contact maps, and integrative modeling. PLoS Genet 14(12):e1007872

Nishino Y, Takahashi Y, Imamoto N, Ishikawa T, Maeshima K (2009) Three-dimensional visualization of a human chromosome using coherent X-ray diffraction. Phys Rev Lett 102(1): 018101

Nishino Y, Eltsov M, Joti Y, Ito K, Takata H, Takahashi Y, Hihara S, Frangakis AS, Imamoto N, Ishikawa T, Maeshima K (2012) Human mitotic chromosomes consist predominantly of irregularly folded nucleosome fibres without a $30-\mathrm{nm}$ chromatin structure. EMBO J 31(7):1644-1653

Nowell PC, Hungerford DA (1960) A minute chromosome in human chronic granulocytic leukemia. Science 132:1497

Nozaki T, Imai R, Tanbo M, Nagashima R, Tamura S, Tani T et al (2017) Dynamic organization of chromatin domains revealed by super-resolution live-cell imaging. Mol Cell 67(2):282293

Ohno M, Priest DG, Taniguchi Y (2018) Nucleosome-level 3D organization of the genome. Biochem Soc Trans 46(3):491501 
Olins AL, Olins DE (1974) Spheroid chromatin units ( $v$ bodies). Science 183(4122):330-332

Otterstrom J, Castells-Garcia A, Vicario C, Gomez-Garcia PA, Cosma MP, Lakadamyali M (2019) Super-resolution microscopy reveals how histone tail acetylation affects DNA compaction within nucleosomes in vivo. Nucleic Acids Res 47(16):8470-8484

Ou HD, Phan S, Deerinck TJ, Thor A, Ellisman MH, O'shea CC (2017) ChromEMT: visualizing 3D chromatin structure and compaction in interphase and mitotic cells. Science 357(6349): eaag0025

Pelicci S, Diaspro A, Lanzanò L (2019) Chromatin nanoscale compaction in live cells visualized by acceptor-donor ratio corrected FRET between DNA dyes. bioRxiv 671784(10)

Phengchat R, Takata H, Morii K, Inada N, Murakoshi H, Uchiyama S, Fukui K (2016) Calcium ions function as a booster of chromosome condensation. Sci Rep 6:38281

Poonperm R, Takata H, Hamano T, Matsuda A, Uchiyama S, Hiraoka Y, Fukui K (2015) Chromosome scaffold is a double-stranded assembly of scaffold proteins. Sci Rep 5(1):1-10

Potapova TA, Unruh JR, Yu Z, Rancati G, Li H, Stampfer MR, Gerton JL (2019) Superresolution microscopy reveals linkages between ribosomal DNA on heterologous chromosomes. J Cell Biol 218(8):2492-2513

Rabl C (1885) Uber Zelltheilung. Wilhelm Engelmann, Leipzig

Ricci MA, Manzo C, García-Parajo MF, Lakadamyali M, Cosma MP (2015) Chromatin fibers are formed by heterogeneous groups of nucleosomes in vivo. Cell 160(6):1145-1158

Rieder CL, Khodjakov A (2003) Mitosis through the microscope: advances in seeing inside live dividing cells. Science 300(5616):91-96

Robinson PJ, Fairall L, Huynh VA, Rhodes D (2006) EM measurements define the dimensions of the " $30-\mathrm{nm}$ " chromatin fiber: evidence for a compact, interdigitated structure. Proc Natl Acad Sci 103(17):6506-6511

Sahl SJ, Hell SW (2019) High-resolution 3D light microscopy with STED and RESOLFT. In: High resolution imaging in microscopy and ophthalmology. Springer, Cham, pp 3-32

Samejima K, Samejima I, Vagnarelli P, Ogawa H, Vargiu G, Kelly DA et al (2012) Mitotic chromosomes are compacted laterally by KIF4 and condensin and axially by topoisomerase II $\alpha$. J Cell Biol 199(5):755-770

Sandberg AA, Koepf GF, Isihara T, Hauschka TS (1961) An XYY human male. Lancet II:488-489

Schermelleh L, Carlton PM, Haase S, Shao L, Winoto L, Kner P et al (2008) Subdiffraction multicolor imaging of the nuclear periphery with $3 \mathrm{D}$ structured illumination microscopy. Science 320(5881):1332-1336

Schermelleh L, Ferrand A, Huser T, Eggeling C, Sauer M, Biehlmaier O, Drummen GP (2019) Super-resolution microscopy demystified. Nat Cell Biol 21(1):72-84

Schoen I, Ries J, Klotzsch E, Ewers H, Vogel V (2011) Bindingactivated localization microscopy of DNA structures. Nano Lett 11(9):4008-4011

Schor, I. E., Llères, D., Risso, G. J., Pawellek, A., Ule, J., Lamond, A. I., \& Kornblihtt, A. R. (2012). Perturbation of chromatin structure globally affects localization and recruitment of splicing factors. PloS one, 7(11), e48084. (11)

Schröck E, Du Manoir S, Veldman T, Schoell B, Wienberg J, Ferguson-Smith MA et al (1996) Multicolor spectral karyotyping of human chromosomes. Science 273(5274): 494-497

Sherrard A, Bishop P, Panagi M, Villagomez MB, Alibhai D, Kaidi A (2018) Streamlined histone-based fluorescence lifetime imaging microscopy (FLIM) for studying chromatin organisation. Biology open 7(3):bio031476

Spagnol ST, Dahl KN (2016) Spatially resolved quantification of chromatin condensation through differential local rheology in cell nuclei fluorescence lifetime imaging. PLoS One 11(1): e0146244 (15)

Sparks H, Kondo H, Hooper S, Munro I, Kennedy G, Dunsby C et al (2018) Heterogeneity in tumor chromatin-doxorubicin binding revealed by in vivo fluorescence lifetime imaging confocal endomicroscopy. Nat Commun 9(1):1-14

Speicher MR, Ballard SG, Ward DC (1996) Karyotyping human chromosomes by combinatorial multi-fluor FISH. Nat Genet 12(4):368-375

Strzyz P (2020) CRISPR-Cas9 wins Nobel. Nat Rev Mol Cell Biol 21(12):714-714

Suhling K, Hirvonen LM, Levitt JA, Chung PH, Tregidgo C, Le Marois A et al (2015) Fluorescence lifetime imaging (FLIM): basic concepts and some recent developments. Medical Photonics 27:3-40

Sumner AT (1982) The nature and mechanisms of chromosome banding. Cancer Genet Cytogenet 6(1):59-87

Szczurek AT, Prakash K, Lee HK, Żurek-Biesiada DJ, Best G, Hagmann M, Dobrucki JW, Cremer C, Birk U (2014) Single molecule localization microscopy of the distribution of chromatin using Hoechst and DAPI fluorescent probes. Nucleus 5(4):331-340

Tjio JH, Levan A (1956) The chromosome number of man. In: Problems of birth defects. Springer, Dordrecht, pp 112-118

Tobias ES, Connor M, Ferguson-Smith M (2011) Essential medical genetics, includes desktop edition. Wiley, Hoboken

Truckenbrodt S, Sommer C, Rizzoli SO, Danzl JG (2019) A practical guide to optimization in X10 expansion microscopy. Nat Protoc 14(3):832-863

Tseng TY, Liu SY, Wang CL, Chang TC (2020) Antisense oligonucleotides used to identify telomeric G-Quadruplexes in metaphase chromosomes and fixed cells by fluorescence lifetime imaging microscopy of o-BMVC foci. Molecules 25(18):4083 (7)

Tsien RY (2010) The 2009 Lindau Nobel Laureate Meeting: Roger Y. Tsien. Chemistry 2008. JoVE (Journal of Visualized Experiments) (35):e1575

Tuijtel MW, Koster AJ, Jakobs S, Faas FG, Sharp TH (2019) Correlative cryo super-resolution light and electron microscopy on mammalian cells using fluorescent proteins. Sci Rep 9(1):1-11

Valouev A, Johnson SM, Boyd SD, Smith CL, Fire AZ, Sidow A (2011) Determinants of nucleosome organization in primary human cells. Nature 474(7352):516-520

Vangindertael J, Camacho R, Sempels W, Mizuno H, Dedecker P, Janssen KPF (2018) An introduction to optical superresolution microscopy for the adventurous biologist. Methods and applications in fluorescence 6(2):022003

Vicidomini G, Bianchini P, Diaspro A (2018) STED superresolved microscopy. Nat Methods 15(3):173-182

Visvanathan A, Ahmed K, Even-Faitelson L, Lleres D, BazettJones DP, Lamond AI (2013) Modulation of higher order chromatin conformation in mammalian cell nuclei can be 
mediated by polyamines and divalent cations. PLoS One 8(6):e67689

Volpi EV, Bridger JM (2008) FISH glossary: an overview of the fluorescence in situ hybridization technique. Biotechniques 45(4):385-409

Walther, N., \& Ellenberg, J. (2018). Quantitative live and superresolution microscopy of mitotic chromosomes. In Methods in cell biology (Vol. 145, pp. 65-90). Academic Press

Wang Y, Maharana S, Wang MD, Shivashankar GV (2014) Super-resolution microscopy reveals decondensed chromatin structure at transcription sites. Sci Rep 4(1):1-7

Wang L, Bateman B, Zanetti-Domingues LC, Moores AN, Astbury S, Spindloe C et al (2019) Solid immersion microscopy images cells under cryogenic conditions with $12 \mathrm{~nm}$ resolution. Commun Biol 2(1):1-11

Woodcock CL, Skoultchi AI, Fan Y (2006) Role of linker histone in chromatin structure and function: H1 stoichiometry and nucleosome repeat length. Chromosom Res 14(1):17-25

Xu J, Liu Y (2019) A guide to visualizing the spatial epigenome with super-resolution microscopy. FEBS J 286(16):30953109

Xu J, Ma H, Jin J, Uttam S, Fu R, Huang Y, Liu Y (2018) Superresolution imaging of higher-order chromatin structures at different epigenomic states in single mammalian cells. Cell Rep 24(4):873-882

$\mathrm{Xu}$ J, Ma H, Ma H, Jiang W, Mela CA, Duan M et al (2020) Superresolution imaging reveals the evolution of higher-order chromatin folding in early carcinogenesis. Nat Commun 11(1):1-17

Yan H, Nazaretski E, Lauer K, Huang X, Wagner U, Rau C, Yusuf M, Robinson I, Kalbfleisch S, Li L, Bouet N, Zhou J, Conley R, Chu YS (2016) Multimodality hard-x-ray imaging of a chromosome with nanoscale spatial resolution. Sci Rep 6: 20112
Yardimci S, Burnham DR, Terry SY, Yardimci H (2020) Threedimensional super-resolution fluorescence imaging of DNA. Sci Rep 10(1):1-8

Yusuf M, Bauer DL, Lipinski DM, MacLaren RE, Wade-Martins R, Mir KU, Volpi EV (2011) Combining M-FISH and Quantum Dot technology for fast chromosomal assignment of transgenic insertions. BMC Biotechnol 11(1):121

Yusuf M, Leung K, Morris KJ, Volpi EV (2013) Comprehensive cytogenomic profile of the in vitro neuronal model $\mathrm{SH}$ SY5Y. Neurogenetics 14(1):63-70

Yusuf M, Chen B, Hashimoto T, Estandarte AK, Thompson G, Robinson I (2014) Staining and embedding of human chromosomes for 3-D serial block-face scanning electron microscopy. Biotechniques 57(6):302-307

Yusuf M, Kaneyoshi K, Fukui K, Robinson I (2019) Use of 3D imaging for providing insights into high-order structure of mitotic chromosomes. Chromosoma 128(1):7-13

Yusuf M, Farooq S, Robinson I, Lalani EN (2020) Cryo-nanoscale chromosome imaging-future prospects. Biophys Rev:1-7

Zhang Y, Li G (2020) Advances in technologies for 3D genomics research. Sci China Life Sci 63(6):811-824

Zhou Y, Wang P, Tian F, Gao G, Huang L, Wei W, Xie XS (2017) Painting a specific chromosome with CRISPR/Cas9 for livecell imaging. Cell Res 27(2):298-301

Zwettler FU, Reinhard S, Gambarotto D, Bell TD, Hamel V, Guichard P, Sauer M (2020) Molecular resolution imaging by post-labeling expansion single molecule localization microscopy (Ex-SMLM). BioRxiv

Publisher's Note Springer Nature remains neutral with regard to jurisdictional claims in published maps and institutional affiliations. 